\section{$\underset{\substack{\text { hommes } \\ \text { \& migrations }}}{ }$}

\section{Hommes \& migrations}

Revue française de référence sur les dynamiques

migratoires

1286-1287 | 2010

Les migrations subsahariennes

\title{
Odyssées africaines
}

\section{Marie Poinsot}

\section{CpenEdition \\ Journals}

\section{Édition électronique}

URL : http://journals.openedition.org/hommesmigrations/1695

DOI : 10.4000/hommesmigrations.1695

ISSN : 2262-3353

\section{Éditeur}

Musée national de l'histoire de l'immigration

Édition imprimée

Date de publication : 1 juillet 2010

Pagination : 1

ISSN : 1142-852X

Référence électronique

Marie Poinsot, "Odyssées africaines », Hommes \& migrations [En ligne], 1286-1287 | 2010, mis en ligne le 29 mai 2013, consulté le 22 septembre 2020. URL : http://journals.openedition.org/

hommesmigrations/1695; DOI : https://doi.org/10.4000/hommesmigrations.1695 


\section{Odyssées africaines \\ Par Marie Poinsot, rédactrice en chef}

Contacté par le Groupe de recherches et de réalisations pour le développement rural (GRDR), qui souhaitait marquer les 40 ans de ses activités en offrant un état des lieux des recherches sur les migrations subsahariennes, Hommes et Migrations a proposé de publier pour cette occasion un numéro double. Son objectif est de couvrir au moins trois volets de ces migrations : la diversité des flux qui concernent ici essentiellement l'Afrique de l'Ouest, la complexité de la présence africaine sur le territoire français et les conséquences de ces migrations sur le développement des pays d'origine. Vaste programme qui fait écho à un autre dossier publié l'année dernière sur les circulations internes au continent africain (L'Afrique en mouvement, $n^{\circ} 1279$, mai-juin 2009) et le complète utilement.

Le fil rouge de ce dossier est la mise au jour des caractéristiques de ces migrations subsahariennes dans un contexte de mondialisation qui accélère et multiplie les circulations. Le continent africain serait-il entré tardivement dans ce processus ? II apparaît au contraire que des migrations multiformes et multipolaires se déploient depuis longtemps en Afrique. Les déplacements transfrontaliers, souvent pendulaires, sont d'ailleurs plus importants en nombre que les flux vers d'autres continents, compte tenu des restrictions d'accès et des contrôles de plus en plus fermes mis en place notamment par l'Union européenne. Des migrations de transit apparaissent ainsi dans certaines zones, le long de barrières infranchissables.

L'Hexagone est-il la seule destination de ces migrants ? De nos jours, la France se situe derrière la Grande-Bretagne pour l'accueil des migrants africains. Les migrants tentent également leur chance dans les pays méditerranéens (Italie, Espagne, Portugal, Grèce), tandis que plus d'un tiers partent désormais aux États-Unis. Le lien historique avec l'ancienne métropole tend à se déliter, malgré le partage d'une langue commune.

Une autre particularité de ces migrations réside dans le souci d'organisation collective des migrants en vue de participer au développement de leur pays d'origine, soit par des transferts financiers, soit en portant des projets correspondant aux besoins de ces pays.

Ce dossier montre aujourd'hui la vitalité de leurs actions tout en interrogeant les conditions réelles et les limites de leurs investissements. Car les migrants semblent toujours rencontrer des difficultés à être reconnus comme des acteurs à part entière du développement de l'Afrique aux côtés des collectivités territoriales, des associations et de l'État français.

En France, ces migrations font l'objet d'une actualité récurrente en alimentant des stéréotypes dans l'opinion. À l'inverse, des travaux encore peu nombreux montrent la diversité des formes d'installation et d'insertion dans la société française. Si le poids de l'histoire coloniale sur les représentations des Africains est devenu plus récemment un thème de recherche important, la compréhension des conséquences des indépendances africaines dans les configurations de ces migrations reste un chantier encore peu couvert.

La revue s'est également intéressée à la vitalité dont fait preuve l'immigration subsaharienne dans le domaine culturel. Une énergie créatrice qui va à l'encontre des images négatives et des discriminations dont sont victimes les migrants africains dans la société française. Les formes d'expression - notamment dans le domaine de la musique, de la littérature, de la mode ou de la photographie - suscitent des échos chaleureux, même si les artistes et les collectifs africains rencontrent des difficultés dans leurs parcours. Leur dynamisme témoigne d'une volonté forte de présenter un autre visage de l'Afrique et d'évoquer des expériences migratoires au-delà de tout prisme victimaire. 